\title{
A study on gr*-closed sets in Bitopological Spaces
}

\author{
${ }^{1}$ K.Indirani, ${ }^{2}$ P.Sathishmohan and ${ }^{3}$ V.Rajendran \\ ${ }^{I}$ Department of Mathematics, Nirmala College for Woman, Coimbatore, TN, India. \\ ${ }^{2,3}$ Department of Mathematics, KSG college, Coimbatore, TN, India.
}

\begin{abstract}
In this paper we introduce and investigate the notions of $g r^{*}$-closed set, gr*-open set, gr*continuous, gr*-neighbourhood, gr*O-connected spaces, pairwise gr*O-compact spaces in Bitopological Spaces.

Keywords: (i,j) gr*-closed sets, $(i, j)$ gr*-open sets, $D_{r}^{*}(i, j)$ - $\sigma_{k}$-continuous, $\left(\tau_{i}, \tau_{j}\right)$-gr*-neighbourhood, pairwise $g r * O$-connected, pairwise $g r *$ open cover, pairwise $g r * O$-compact .
\end{abstract}

\section{Introduction:}

A triple $\left(\mathrm{X}, \tau_{1}, \tau_{2}\right)$ where $\mathrm{X}$ is a non-empty set and $\tau_{1}$ and $\tau_{2}$ are topologies on $\mathrm{X}$ is called a bitopological space and kelly [7] initiated the study of such spaces. In 1985, Fukutake [2] introduced the concept of g-closed sets in bitopological spaces and after that several authors turned their attention towards generalizations of various concepts of topology by considering bitopological spaces and Indirani et.al.[5] introduced gr*-closed sets in topological spaces and investigated its relationship with the other types of closed sets. The purpose of the present paper is to define a new class of closed sets called (i,j) gr*-closed sets and we discuss some basic properties of $(i, j)$ gr*-closed sets in bitopological spaces.

\section{Preliminaries:}

If $\mathrm{A}$ is a subset of $\mathrm{X}$ with a topology $\tau$, then the closure of $\mathrm{A}$ is denoted by $\tau$-cl( $\mathrm{A}) \operatorname{of} \mathrm{cl}(\mathrm{A})$, the interior of $\mathrm{A}$ is denoted by $\tau$-int(A) of int(A) and the complement of $\mathrm{A}$ in $\mathrm{X}$ is denoted by $\mathrm{A}^{\mathrm{C}}$.

Definition: 2.1. A subset $A$ of a topological space $(X, \tau)$ is called

(i) A generalizad closed set [9] ( briefly g-closed set) if $\operatorname{cl}(\mathrm{A}) \subseteq \mathrm{U}$ whenever $\mathrm{A} \subseteq \mathrm{U}$ ad $\mathrm{U}$ is open in $\mathrm{X}$.

(ii) a generalized open set (briefly g-closed set) if $\mathrm{A}^{\mathrm{c}}$ is g-closed in $\mathrm{X}$.

(iii) a regular open set [11] if $\mathrm{A}=\operatorname{int}(\mathrm{cl}(\mathrm{A}))$

(iv) a semi-open set [8] if $\mathrm{A} \subseteq \mathrm{cl}$ (int (A))

Definition 2.2 - the intersection of all pre closed sets containing A is called the pre-closure of $\mathrm{A}$ and it si denoted by $\tau$-pcl(A) or pcl(A).

Throughout this paper $\mathrm{X}$ and $\mathrm{Y}$ always represent nonempty bitoplogical spaces $\left(\mathrm{X}, \tau_{1}, \tau_{2}\right)$ and $\left(\mathrm{Y}, \sigma_{1}, \sigma_{2}\right)$ on which no separation axioms are assumed unless explicitly metioned and the integers $\mathrm{I}, \mathrm{j}, \mathrm{k} \in\{1,2\}$. For a subset $\mathrm{A}$ of $\mathrm{X}, \tau_{\mathrm{i}}-\mathrm{cl}(\mathrm{A})$ (resp. $\tau_{\mathrm{i}}$-int(A), $\tau_{\mathrm{i}}$-pcl(A)) denote the closure (resp. interior, preclosure) of A with respect to the toplogy $\tau_{\mathrm{i}}$, by $\mathrm{GO}\left(\mathrm{X}, \tau_{\mathrm{i}}\right)$ and the family of all $\tau_{\mathrm{j}}$-closed set is denoted by the symbol $\mathrm{F}_{\mathrm{j}}$. By $(\mathrm{I}, \mathrm{j})$ we mean the pair of topologies $\left(\tau_{\mathrm{i}}, \tau_{\mathrm{j}}\right)$.

Definition 2.3- A subset A of a topological space $\left(X, \tau_{1}, \tau_{2}\right)$ is called

(i) (i,j)-g-closed [2] if $\tau_{\mathrm{j}}$-cl( $\left.\mathrm{A}\right) \subseteq \mathrm{U}$ whenever $\mathrm{A} \subseteq \mathrm{U}$ and $\mathrm{U} \in \tau_{\mathrm{i}}$.

(ii) $(\mathrm{i}, \mathrm{j})$-rg-closed $[1]$ if $\tau_{\mathrm{j}} \mathrm{cl}(\mathrm{A}) \subseteq \mathrm{U}$ whenever $\mathrm{A} \subseteq \mathrm{U}$ and $\mathrm{U}$ is regular open in $\tau_{\mathrm{i}}$

(iii) (i,j)-gpr-closed [4] if $\tau_{\mathrm{j}}$-pcl( $\left.\mathrm{A}\right) \subseteq \mathrm{U}$ whenever $\mathrm{A} \subseteq \mathrm{U}$ and $\mathrm{U}$ is regular open in $\tau_{\mathrm{i}}$

(iv) (i,j)- $g$-closed [4] if $\tau_{\mathrm{j}}$-cl( $\left.\mathrm{A}\right) \subseteq \mathrm{U}$ whenever $\mathrm{A} \subseteq \mathrm{U}$ and $\mathrm{U}$ is semi-open in $\tau_{\mathrm{i}}$.

(v) (i,j)-g ${ }^{*}$-closed [12] if $\tau_{\mathrm{j}}$-Cl( $(\mathrm{A}) \subseteq \mathrm{U}$ whenever $\mathrm{A} \subseteq \mathrm{U}$ and $\mathrm{U} \in \mathrm{GO}\left(\mathrm{X}, \tau_{\mathrm{i}}\right)$.

The family of all(i,j)-g-closed (resp. (i,j)-rg-closed, (i,j)-gpr-closed, (i,j)-wg-closed and (i,j)-w-closed) subsets of a bitoplogical space $\left(\mathrm{X}, \tau_{1}, \tau_{2}\right)$ is denoted by $\mathrm{D}(\mathrm{I}, \mathrm{j})\left(\right.$ resp. $\mathrm{D}_{\mathrm{r}}(\mathrm{I}, \mathrm{j}), \zeta(\mathrm{i}, \mathrm{j}), \mathrm{W}(\mathrm{i}, \mathrm{j})$ and $\left.\mathrm{C}(\mathrm{i}, \mathrm{j})\right)$.

Definition 2.5 A map f: $\left(\mathrm{X}, \tau_{1}, \tau_{2}\right) \rightarrow\left(\left(\mathrm{Y}, \tau_{1}, \tau_{2}\right)\right.$ is called:

(1) $\tau_{\mathrm{j}}-\sigma_{\mathrm{k}}$-continuous $[10]$ if $\mathrm{f}^{1}(\mathrm{~V}) \in \tau_{\mathrm{j}}$ for every $\mathrm{V} \in \sigma_{\mathrm{k}}$.

(2) $\mathrm{D}(\mathrm{i}, \mathrm{j})-\sigma_{\mathrm{k}}$ continuous [10] (resp. $\mathrm{D}^{*}(\mathrm{i}, \mathrm{j})-\sigma_{\mathrm{k}}$-continuous [12], $\mathrm{D}_{\mathrm{r}}(\mathrm{i}, \mathrm{j})-\sigma_{\mathrm{k}}$-continuous [1], $\xi(\mathrm{i}, \mathrm{j})-\sigma_{\mathrm{k}}$-continuous [4], W(I,j)- $\sigma_{\mathrm{k}}$-continuous[3], C(i,j)- $\sigma_{\mathrm{k}}$-continuous[4] and $\mathrm{D}_{\mathrm{r}}^{*}(\mathrm{i}, \mathrm{j})-\sigma_{\mathrm{k}}$-continuous [6]) if the inverse image of every $\sigma_{k}$-closed set is $(\mathrm{i}, \mathrm{j})$-g-closed (resp. $(\mathrm{i}, \mathrm{j})$ - $\mathrm{g}^{*}$-closed, $(\mathrm{i}, \mathrm{j})$-rg-closed, (i,j)-gpr-closed, (i,j)-wg-closed, $(\mathrm{i}, \mathrm{j})$-wclosed and $(\mathrm{i}, \mathrm{j})$ gr*-closed) set in $\left(\mathrm{X}, \tau_{1}, \tau_{2}\right)$. 


\section{III. (i,j) gr*-closed sets}

Definition 3.1: A subset A of a bitopological space $\left(X, \tau_{1}, \tau_{2}\right)$ is said to be an (i,j) gr*-closed set if $\tau_{j}$-rcl(A) $\subseteq U$, whenever $\mathrm{A} \subseteq \mathrm{U}$ and $\mathrm{U}$ is $\tau_{\mathrm{i}}$-g-open.

We denote the family of all $(\mathrm{i}, \mathrm{j})$ gr*-closed set in $\left(\mathrm{X}, \tau_{1}, \tau_{2}\right)$ by $\mathrm{D}_{\mathrm{r}}^{*}(\mathrm{i}, \mathrm{j})$.

Remark 3.2: By setting $\tau_{1}=\tau_{2}$ in Definition 3.1, a $(1,2)$ gr*-closed sets is a gr*-closed sets.

Proposition 3.3: If $A$ is $\tau_{\mathrm{j}}$-closed subset of $\left(X, \tau_{1}, \tau_{2}\right)$ then $A$ is $(i, j)$ gr*-closed.

Proof: Let $A$ be $\tau_{\mathrm{j}}$-closed subset of $\left(\mathrm{X}, \tau_{1}, \tau_{2}\right)$. To prove that $\mathrm{A}$ is $(\mathrm{i}, \mathrm{j})$ gr*-closed. Let $\mathrm{U}$ be any g-open in $\left(\mathrm{X}, \tau_{\mathrm{i}}\right)$ such that $A \subseteq U$. Since every r-closed sets are closed, so that $A$ is $\tau_{j}$-closed, it follows that $\tau_{j}$-cl $(A) \subseteq \tau_{j}-\operatorname{rcl}(A) \subseteq$ U. This implies that $\tau_{\mathrm{j}}$-rcl $(\mathrm{A}) \subseteq \mathrm{U}$. Hence $\mathrm{A}$ is $(\mathrm{i}, \mathrm{j})$ gr*-closed.

The converse of the above proposition is not true as seen from the following example.

Example 3.4: Let $X=\{a, b, c\}, \tau_{1}=\{\phi,\{a\},\{c\},\{a b\},\{a c\}, X\}, \tau_{2}=\{\phi,\{c\},\{a b\}, X\}$. Then the subset $\{b\}$ and $\{$ bc $\}$ are $(1,2)$-gr*-closed set but not $\tau_{2}$ - closed set in $\left(X, \tau_{1}, \tau_{2}\right)$.

Proposition 3.5: In a bitopological space $\left(\mathrm{X}, \tau_{1}, \tau_{2}\right)$,

(i) Every $\tau_{\mathrm{j}}-\theta$-closed is $(\mathrm{i}, \mathrm{j})$ gr*-closed.

(ii) Every $\tau_{\mathrm{j}}$ - $\delta$-closed is $(\mathrm{i}, \mathrm{j})$ gr*-closed.

(iii) Every $\tau_{\mathrm{j}}$-r-closed is $(\mathrm{i}, \mathrm{j})$ gr*-closed.

Proof: It follows from

(i) Every $\theta$-closed is closed and by proposition 3.3.

(ii) Every $\delta$-closed is closed and by proposition 3.3.

(iii) Every r-closed is closed and by proposition 3.3.

The converse of the above proposition is not true as seen from the following example.

Example 3.6: Let $X=\{a, b, c\}, \tau_{1}=\{\phi,\{a\},\{b\},\{a b\}, X\}$ and $\tau_{2}=\{\phi,\{b\},\{a c\}, X\}$. Then the subset $\{b c\}$ is $(1,2)-$ gr*-closed set but not $\tau_{2}-\theta-$ closed set in $\left(X, \tau_{1}, \tau_{2}\right)$.

Example 3.7: Let $X=\{a, b, c\}, \tau_{1}=\{\phi,\{b\},\{a c\}, X\}$ and $\tau_{2}=\{\phi,\{a\},\{b\},\{a b\}, X\}$. Then the subset $\{a c\}$ is $(1,2)-$ gr*-closed set but not $\tau_{2}-\delta$ - closed set in $\left(X, \tau_{1}, \tau_{2}\right)$.

Example 3.8: Let $X=\{a, b, c\}, \tau_{1}=\{\phi,\{a\},\{a b\},\{a c\}, X\}$ and $\tau_{2}=\{\phi,\{a\},\{b\},\{a b\},\{a c\}, X\}$. Then the subset $\{c\}$ is $(1,2)$-gr*-closed set but not $\tau_{2}-r-$ closed set in $\left(X, \tau_{1}, \tau_{2}\right)$.

Proposition 3.9: In a bitopological space $\left(\mathrm{X}, \tau_{1}, \tau_{2}\right)$,

(i) Every $(\mathrm{i}, \mathrm{j})$ gr*-closed is $(\mathrm{i}, \mathrm{j})$-g-closed.

(ii) Every $(\mathrm{i}, \mathrm{j})$ gr*-closed is $(\mathrm{i}, \mathrm{j})$ - $\mathrm{g}^{*}$-closed.

(iii) Every $(\mathrm{i}, \mathrm{j})$ gr*-closed is $(\mathrm{i}, \mathrm{j})$-rg-closed.

(iv) Every (i,j) gr*-closed is $(\mathrm{i}, \mathrm{j})$-gpr-closed.

(v) Every $(i, j)$ gr*-closed is $(i, j)-g$-closed.

Proof: (i) Let A be a (i,j) gr*-closed subset of $\left(X, \tau_{1}, \tau_{2}\right)$. Let $U \in G O\left(X, \tau_{i}\right)$ be such that $A \subseteq U$. Then by hypothesis $\tau_{\mathrm{j}}$-rcl $(\mathrm{A}) \subseteq \mathrm{U}$. This implies $\tau_{\mathrm{j}}$-cl $(\mathrm{A}) \subseteq \mathrm{U}$. Therefore A is $(\mathrm{i}, \mathrm{j})$ gr*-closed.

Proof of (ii) to (v) are similar to (i).

The following examples show that the reverse implications of above proposition are not true.

Example 3.10: Let $X=\{a, b, c\}, \tau_{1}=\{\phi,\{a\}, X\}$ and $\tau_{2}=\{\phi,\{a\},\{c\},\{a b\},\{a c\}, X\}$. Then the subset $\{b\}$ is $(1,2)-$ g-closed but not (1,2)-gr*-closed set.

Example 3.11: Let $X=\{a, b, c\}, \tau_{1}=\{\phi,\{a\},\{a c\}, X\}$ and $\tau_{2}=\{\phi,\{a\},\{c\},\{a b\},\{a c\}, X\}$. Then the subset $\{a\}$ is $(1,2)$-rg-closed but not $(1,2)$-gr*-closed set.

Example 3.12: Let $\mathrm{X}=\{\mathrm{a}, \mathrm{b}, \mathrm{c}\}, \tau_{1}=\{\phi,\{\mathrm{a}\},\{\mathrm{c}\},\{\mathrm{ab}\},\{\mathrm{ac}\}, \mathrm{X}\}$ and $\tau_{2}=\{\phi,\{\mathrm{c}\}, \mathrm{X}\}$. Then the subset $\{\mathrm{ac}\}$ is $(1,2)$-gpr-closed but not $(1,2)$-gr*-closed set.

Example 3.13: Let $X=\{a, b, c\}, \tau_{1}=\{\phi,\{c\},\{a c\},\{b c\}, X\}$ and $\tau_{2}=\{\phi,\{c\}, X\}$. Then the subset $\{a\}$ is $(1,2)-g$ closed but not $(1,2)$-gr*-closed set.

Proposition 3.14: If $A, B \in D_{r}^{*}(i, j)$, then $A \cup B \in D_{r}^{*}(i, j)$.

Proof: Let $\mathrm{U} \in \mathrm{GO}\left(X, \tau_{1}\right)$ be such that $\mathrm{A} \cup \mathrm{B} \subseteq \mathrm{U}$. Then $\mathrm{A} \subseteq \mathrm{U}$ and $\mathrm{B} \subseteq \mathrm{U}$. Since $\mathrm{A}, \mathrm{B} \in \mathrm{D}_{\mathrm{r}}{ }^{*}(\mathrm{i}, \mathrm{j})$, we have $\tau_{\mathrm{j}^{-}}$ $\operatorname{rcl}(\mathrm{A}) \subseteq \mathrm{U}$ and $\tau_{\mathrm{j}}-\mathrm{rcl}(\mathrm{B}) \subseteq \mathrm{U}$. That is $\tau_{\mathrm{j}}-\operatorname{rcl}(\mathrm{A}) \cup \tau_{\mathrm{j}}-\operatorname{rcl}(\mathrm{B}) \subseteq \mathrm{U}$. Also $\tau_{\mathrm{j}}-\operatorname{rcl}(\mathrm{A}) \cup \tau_{\mathrm{j}}-\operatorname{rcl}(\mathrm{B}) \subseteq \mathrm{U}=\tau_{\mathrm{j}}-\operatorname{rcl}(\mathrm{A} \cup \mathrm{B})$ and so $\tau_{\mathrm{j}}-\mathrm{rcl}(\mathrm{A} \cup \mathrm{B}) \subseteq \mathrm{U}$. Therefore $\mathrm{A} \cup \mathrm{B} \in \mathrm{D}_{\mathrm{r}}^{*}(\mathrm{i}, \mathrm{j})$.

Example 3.15: Let $X=\{a, b, c\}, \tau_{1}=\{\phi,\{a\},\{a c\}, X\}$ and $\tau_{2}=\{\phi,\{a\},\{c\},\{a b\},\{a c\}, X\}$. Then the subset $\{b\}$ and $\{c\}$ are $(1,2)$-gr*-closed set and $\{b\} \cup\{c\}=\{b c\}$ is also $(1,2)$-gr*-closed set.

Remark 3.16: The intersection of two $(1,2)$-gr*-closed sets need not be a $(1,2)$-gr*-closed set.

Example 3.17: Let $\mathrm{X}=\{\mathrm{a}, \mathrm{b}, \mathrm{c}\}, \tau_{1}=\{\phi,\{\mathrm{b}\},\{\mathrm{c}\},\{\mathrm{bc}\},\{\mathrm{ac}\}, \mathrm{X}\}$ and $\tau_{2}=\{\phi,\{\mathrm{a}\},\{\mathrm{bc}\}, \mathrm{X}\}$. Then the subset $\{\mathrm{ab}\}$ and $\{b c\}$ are $(1,2)$-gr*-closed set and $\{a b\} \cap\{b c\}=\{b\}$ is not in $(1,2)$-gr*-closed set.

Remark 3.18: $D_{r}^{*}(i, j)$ is generally not equal to $D_{r}^{*}(i, j)$ as seen from the following example. 
Example 3.19: Let $\mathrm{X}=\{\mathrm{a}, \mathrm{b}, \mathrm{c}\}, \tau_{1}=\{\phi,\{\mathrm{a}\},\{\mathrm{b}\},\{\mathrm{ab}\},\{\mathrm{bc}\}, \mathrm{X}\}$ and $\tau_{2}=\{\phi,\{\mathrm{a}\},\{\mathrm{ab}\},\{\mathrm{ac}\}, \mathrm{X}\}$. Then (1,2)-gr*closed set $=\{\phi,\{\mathrm{ac}\}, \mathrm{X}\}$ and $(2,1)$-gr*-closed set $=\{\phi,\{\mathrm{a}\},\{\mathrm{bc}\}, \mathrm{X}\}$.

Proposition 3.20: If $\tau_{1} \subseteq \tau_{2}$ in $\left(\mathrm{X}, \tau_{1}, \tau_{2}\right)$, then $\mathrm{D}_{\mathrm{r}}^{*}(1,2) \subseteq \mathrm{D}_{\mathrm{r}}^{*}(2,1)$.

Proof: Let $A \in D_{r}^{*}(2,1)$. That is $A$ is a $(2,1)$-gr*-closed set. To prove that $A \in D_{r}^{*}(2,1)$. Let $U \in G O\left(X, \tau_{1}\right)$ be such that $A \subseteq U$. Since $\mathrm{GO}\left(X, \tau_{1}\right) \subseteq \mathrm{GO}\left(X, \tau_{2}\right)$, we have $\mathrm{U} \in \mathrm{GO}\left(\mathrm{X}, \tau_{2}\right)$. As A is a $(2,1)$-gr*-closed set, we have $\tau_{1}-\operatorname{rcl}(\mathrm{A}) \subseteq \mathrm{U}$. Since $\tau_{1} \subseteq \tau_{2}$, we have $\tau_{2}-\operatorname{rcl}(\mathrm{A}) \subseteq \tau_{1}-\operatorname{rcl}(\mathrm{A})$ and it follows that $\tau_{2}-\operatorname{rcl}(\mathrm{A}) \subseteq \mathrm{U}$. Hence A is $(1,2)-$ gr*-closed set. That is $\mathrm{A} \in \mathrm{D}_{\mathrm{r}}^{*}(1,2)$. Therefore $\mathrm{D}_{\mathrm{r}}^{*}(1,2) \subseteq \mathrm{D}_{\mathrm{r}}^{*}(2,1)$.

The converse of the above proposition is not true as seen from the following example.

Example 3.21: Let $X=\{a, b, c\}, \tau_{1}=\{\phi,\{b\},\{a b\}, X\}$ and $\tau_{2}=\{\phi,\{b\}, X\}$. Then $D_{r}^{*}(2,1) \subseteq D_{r}^{*}(1,2)$ but $\tau_{1}$ is not contained in $\tau_{2}$.

Proposition 3.22: For each element $x$ of $\left(X, \tau_{1}, \tau_{2}\right),\{x\}$ is $\tau_{i}$-g-closed or $\{x\}^{c}$ is $D_{r}^{*}(1,2)$.

Proposition 3.23: If $\mathrm{A}$ is $(\mathrm{i}, \mathrm{j})$ gr*-closed, then $\tau_{\mathrm{j}}$-cl(A) - A contains no non empty $\tau_{\mathrm{j}}$-g-closed set.

Proof: Let $A$ be a (i,j) gr*-closed set and $F$ be a $\tau_{i}$-g-closed set such that $F \subseteq \tau_{j}-\operatorname{rcl}(A) \subseteq \tau_{j}-\operatorname{rcl}(A)-A$. Since $A \in$ $\mathrm{D}_{\mathrm{r}}^{*}(\mathrm{i}, \mathrm{j})$, we have $\tau_{\mathrm{j}}-\mathrm{cl}(\mathrm{A}) \subseteq \tau_{\mathrm{j}}$-rcl $(\mathrm{A}) \subseteq \mathrm{F}^{\mathrm{c}}$. Thus $\mathrm{F} \subseteq \tau_{\mathrm{j}}-\mathrm{cl}(\mathrm{A}) \cap\left(\tau_{\mathrm{j}}-\mathrm{cl}(\mathrm{A})\right)^{\mathrm{c}}=\phi$.

The converse of the above proposition is not true as seen from the following example.

Example 3.24: Let $X=\{a, b, c\}, \tau_{1}=\{\phi,\{b\},\{c\},\{b c\}, X\}$ and $\tau_{2}=\{\phi,\{a\}, X\}$. Then the subset $A=\{b\}$, then $\tau_{2^{-}}$ $\mathrm{cl}(\mathrm{A})-\mathrm{A}=\{\mathrm{c}\}$ does not contains any non empty $\tau_{1}$-g-closed set but $\mathrm{A}$ is not $(1,2)$-gr*-closed set.

Proposition 3.25: If $\mathrm{A}$ is (i,j) gr*-closed set of $\left(\mathrm{X}, \tau_{1}, \tau_{2}\right)$ such that $\mathrm{A} \subseteq \mathrm{B} \subseteq \mathrm{U} \subseteq \tau_{\mathrm{j}}$-rcl(A), then $\mathrm{B}$ is also an $(\mathrm{i}, \mathrm{j})$ gr*-closed set of $\left(\mathrm{X}, \tau_{1}, \tau_{2}\right)$.

Proposition 3.26: Let $\mathrm{A} \subseteq \mathrm{Y} \subseteq \mathrm{X}$ and suppose that $\mathrm{A}$ is $(\mathrm{i}, \mathrm{j})$-gr*-closed set in $\mathrm{X}$. Then $\mathrm{A}$ is (i,j)-gr*-closed set to Y.

Proposition 3.27: In a bitopological space $\left(X, \tau_{1}, \tau_{2}\right), G R^{*} O\left(X, \tau_{i}\right) \subseteq F_{j}$ iff every subset of $X$ is a $(i, j)$-gr*-closed set.

Proof: Suppose that $G R^{*} \mathrm{O}\left(\mathrm{X}, \tau_{\mathrm{i}}\right) \subseteq \mathrm{F}_{\mathrm{j}}$. Let $\mathrm{A}$ be a subset of $\mathrm{X}$ such that $\mathrm{A} \subseteq \mathrm{U}$, where $\mathrm{U} \in \mathrm{GR} * \mathrm{O}\left(\mathrm{X}, \tau_{\mathrm{i}}\right)$. Then $\tau_{\mathrm{j}^{-}}$ $\operatorname{rcl}(\mathrm{A}) \subseteq \tau_{\mathrm{j}}$-cl( $(\mathrm{A}) \subseteq \tau_{\mathrm{j}}$-cl $(\mathrm{U})=\mathrm{U}$ and hence $\mathrm{A}$ is $(\mathrm{i}, \mathrm{j})$-gr*-closed set. Converserly, suppose that every subset of $\mathrm{X}$ is $(\mathrm{i}, \mathrm{j})$-gr*-closed. Let $\mathrm{U} \in \mathrm{GR} * \mathrm{O}\left(\mathrm{X}, \tau_{\mathrm{i}}\right)$. Since $\mathrm{U}$ is $(\mathrm{i}, \mathrm{j})$-gr*-closed, we have $\tau_{\mathrm{j}}$-rcl $(\mathrm{U}) \subseteq \tau_{\mathrm{j}}$-cl $(\mathrm{U}) \subseteq \mathrm{U}$. Therefore $\mathrm{U} \subseteq \mathrm{F}_{\mathrm{j}}$ and hence $\mathrm{GR} * \mathrm{O}\left(\mathrm{X}, \tau_{\mathrm{i}}\right) \subseteq \mathrm{F}_{\mathrm{j}}$.

\section{IV. (i,j) gr*-open sets}

Definition 4.1: A subset A of a bitopological space $\left(\mathrm{X}, \tau_{1}, \tau_{2}\right)$ is said to be $\left(\tau_{\mathrm{i}}, \tau_{\mathrm{j}}\right)$ gr*-open if its complement is $\left(\tau_{i}, \tau_{j}\right)$ gr*- closed in $\left(X, \tau_{1}, \tau_{2}\right)$.

Proposition 4.2: In a bitopological space (X, $\left.\tau_{1}, \tau_{2}\right)$,

(i) Every $\tau_{\mathrm{j}}-\theta$-open set is $(\mathrm{i}, \mathrm{j})$ gr*-open.

(ii) Every $\tau_{j}-\delta$-open set is $(\mathrm{i}, \mathrm{j}) \mathrm{gr} *$ - open.

(iii) Every $\tau_{\mathrm{j}}$-r-open set is $(\mathrm{i}, \mathrm{j})$ gr*- open.

Proposition 4.3: In a bitopological space (X, $\left.\tau_{1}, \tau_{2}\right)$,

(i) Every $(\mathrm{i}, \mathrm{j})$ gr*-open is $(\mathrm{i}, \mathrm{j})$-g- open.

(ii) Every $(i, j)$ gr*- open is $(i, j)-g *$ - open.

(iii) Every $(\mathrm{i}, \mathrm{j})$ gr*- open is $(\mathrm{i}, \mathrm{j})$-rg- open.

(iv) Every $(i, j)$ gr*- open is (i,j)-gpr- open.

(v) Every $(i, j)$ gr*- open is $(i, j)-g$ - open.

Proposition 4.4: A subset $A$ of a bitopological space $\left(X, \tau_{1}, \tau_{2}\right)$ is $\left(\tau_{i}, \tau_{j}\right)$ gr*- open iff $F \subseteq \tau_{\mathrm{j}}$-rint $(A)$ whenever $F$ is $\tau_{\mathrm{i}}$-g-closed and $\mathrm{F} \subseteq \mathrm{A}$.

Proof: Necessity. Let $A$ be a $\left(\tau_{i}, \tau_{j}\right)$ gr*-open set in $X$ and $F$ be a $\tau_{1}$-g-closed set such that $F \subseteq A$. Then $F^{c} \subseteq A^{c}$ where $F^{c}$ is $\tau_{1}$-g-open and $A^{c}$ is $\left(\tau_{i}, \tau_{j}\right)$ gr*- closed implies $\tau_{j}$-rcl $(A) \subseteq\left(F^{c}\right), \tau_{j}(\operatorname{rint}(A)){ }^{c} \subseteq F^{c}$. Hence $F \subseteq \tau_{j}$ $\operatorname{rint}(A)$. Sufficiency. Let $F \subseteq \tau_{j}$-rint $(A)$ whenever $F$ is $\tau_{1}$-g-closed and $F \subseteq A$. Then $A^{c} \subseteq F^{c}=G$ and $G$ is $\tau_{i}$-gopen. Then $G^{c} \subseteq A$ implies $G^{c} \subseteq \tau_{j}-\operatorname{rint}(A)$ or $\tau_{j}-\operatorname{rcl}\left(A^{c}\right)=\left(\tau_{j}-\operatorname{rint}(A)\right)^{c} \subseteq G$. Then $A^{c}$ is $\left(\tau_{i}, \tau_{j}\right)$ gr*- closed or $A$ is $\left(\tau_{i}, \tau_{j}\right)$ gr*- open.

\section{V. (i,j) gr*-continuous map}

Definition 5.1: A map f: $\left(\mathrm{X}, \tau_{1}, \tau_{2}\right) \rightarrow\left(\mathrm{Y}, \sigma_{1}, \sigma_{2}\right)$ is called $\mathrm{D}_{\mathrm{r}}^{*}(\mathrm{i}, \mathrm{j})-\sigma_{\mathrm{k}}$-continuous if the inverse image of every $\sigma_{\mathrm{k}^{-}}$ closed set is $(\mathrm{i}, \mathrm{j})$ gr*-closed set.

Proposition 5.2: If $\mathrm{f}:\left(\mathrm{X}, \tau_{1}, \tau_{2}\right) \rightarrow\left(\mathrm{Y}, \sigma_{1}, \sigma_{2}\right)$ is $\tau_{\mathrm{j}}-\sigma_{\mathrm{k}}$-continuous, then it is $\mathrm{D}_{\mathrm{r}}^{*}(\mathrm{i}, \mathrm{j})-\sigma_{\mathrm{k}}$-continuous but not conversely. 
Example 5.3: Let $\mathrm{X}=\mathrm{Y}=\{\mathrm{a}, \mathrm{b}, \mathrm{c}\}, \tau_{1}=\{\phi,\{\mathrm{a}\},\{\mathrm{b}\},\{\mathrm{ab}\}, \mathrm{X}\}, \tau_{2}=\{\phi,\{\mathrm{b}\},\{\mathrm{ac}\}, \mathrm{X}\}, \sigma_{1}=\{\phi,\{\mathrm{a}\}, \mathrm{X}\}$ and $\sigma_{2}=$ $\{\phi,\{c\}, X\}$. Define a map f: $\left(X, \tau_{1}, \tau_{2}\right) \rightarrow\left(Y, \sigma_{1}, \sigma_{2}\right)$ by $f(a)=a, f(b)=c, f(c)=b$. Then $f$ is $D_{r}^{*}(i, j)-\sigma_{2}$-continuous, but not $\tau_{1}-\sigma_{2}$-continuous.

Proposition 5.4: If $\mathrm{f}:\left(\mathrm{X}, \tau_{1}, \tau_{2}\right) \rightarrow\left(\mathrm{Y}, \sigma_{1}, \sigma_{2}\right)$ is $\mathrm{D}_{\mathrm{r}}^{*}(\mathrm{i}, \mathrm{j})-\sigma_{\mathrm{k}}$-continuous then it is

(i) $\mathrm{D}(\mathrm{i}, \mathrm{j})-\sigma_{\mathrm{k}}$-continuous.

(ii) $\mathrm{D}^{*}(\mathrm{i}, \mathrm{j})-\sigma_{\mathrm{k}}$-continuous.

(iii) $D_{\mathrm{r}}(\mathrm{i}, \mathrm{j})-\sigma_{\mathrm{k}}$-continuous.

(iv) $\zeta(\mathrm{i}, \mathrm{j})-\sigma_{\mathrm{k}}$-continuous.

(v) $\mathrm{C}(\mathrm{i}, \mathrm{j})-\sigma_{\mathrm{k}}$-continuous.

Proof: (i) Let $\mathrm{V}$ be a $\sigma_{\mathrm{k}}$-closed set in $\left(\mathrm{Y}, \sigma_{1}, \sigma_{2}\right)$. Since $\mathrm{f}$ is $\mathrm{D}_{\mathrm{r}}^{*}(\mathrm{i}, \mathrm{j})-\sigma_{\mathrm{k}}$-continuous,

$\mathrm{f}^{1}(\mathrm{~V})$ is $(\mathrm{i}, \mathrm{j})$-gr*-closed in $\left(\mathrm{X}, \tau_{1}, \tau_{2}\right)$. Then by Proposition 3.9, $\mathrm{f}^{1}(\mathrm{~V})$ is $(\mathrm{i}, \mathrm{j})$-g-closed. Therefore $\mathrm{f}$ is $\mathrm{D}(\mathrm{i}, \mathrm{j})-\sigma_{\mathrm{k}}$ continuous.

proof of (ii) to (v) are similar to (i), using Proposition 3.9.

However the reverse implications of the above proposition are not true in general as seen from the following example.

Example 5.5: Let $X=Y=\{a, b, c\}, \tau_{1}=\{\phi,\{a\},\{b\},\{a b\},\{b c\}, X\}, \tau_{2}=\{\phi,\{b\},\{a c\}, X\}, \sigma_{1}=\{\phi,\{a b\}, X\}$ and $\sigma_{2}$ $=\{\phi,\{b c\}, X\}$. Then the identity map f on $\mathrm{X}$ is $\mathrm{D}_{\mathrm{r}}(\mathrm{i}, \mathrm{j})-\sigma_{\mathrm{k}}$ - continuous and $\zeta(\mathrm{i}, \mathrm{j})-\sigma_{\mathrm{k}}$-continuous but not $\mathrm{D}_{\mathrm{r}}^{*}(\mathrm{i}, \mathrm{j})$ - $\sigma_{2}$-continuous.

Example 5.6: Let $\mathrm{X}=\mathrm{Y}=\{\mathrm{a}, \mathrm{b}, \mathrm{c}\}, \tau_{1}=\{\phi,\{\mathrm{a}\}, \mathrm{X}\}, \tau_{2}=\{\phi,\{\mathrm{a}\},\{\mathrm{c}\},\{\mathrm{ab}\},\{\mathrm{ac}\}, \mathrm{X}\}, \sigma_{1}=\{\phi,\{\mathrm{b}\}, \mathrm{X}\}$ and $\sigma_{2}=$ $\{\phi,\{a b\}, X\}$. Then the identity map f on $X$ is $D(i, j)-\sigma_{k}-$ continuous, $D^{*}(i, j)-\sigma_{k^{-}}$-continuous and $C(i, j)-\sigma_{k^{-}}$ continuous but not $D_{r}^{*}(i, j)-\sigma_{2}$-continuous.

\section{VI. $\quad\left(\tau_{\mathbf{i}}, \tau_{\mathbf{j}}\right)$-gr*-Neighbourhood}

Definition 6.1. Let $\left(\mathrm{X}, \tau_{\mathrm{i}}, \tau_{\mathrm{j}}\right)$ be bitopological space, and let $\mathrm{g} \in \mathrm{X}$. A subset $\mathrm{N}$ of $\mathrm{X}$ is said to be, $\left(\tau_{\mathrm{i}}, \tau_{\mathrm{j}}\right)$-gr*neighbourhood (briefly $\left(\tau_{i}, \tau_{\mathrm{j}}\right)$ - gr*-nhd) if a point $\mathrm{g}$ if and only if there exists a $\left(\tau_{\mathrm{i}}, \tau_{\mathrm{j}}\right)$ - gr*-open set $\mathrm{G}$ such that $\mathrm{g} \in \mathrm{G} \subseteq \mathrm{N}$.

The set of all $\left(\tau_{i}, \tau_{\mathrm{j}}\right)$ - gr*-nhd of a point $\mathrm{g}$ is denoted by $\left(\tau_{\mathrm{i}}, \tau_{\mathrm{j}}\right)$ - gr*-N(g).

Proposition 6.2. Every $\tau_{\mathrm{i}}$-nhd of $\mathrm{g} \in \mathrm{X}$ is a $\left(\tau_{\mathrm{i}}, \tau_{\mathrm{j}}\right)$ - gr*-nhd of $\mathrm{g} \in \mathrm{X}$.

Proof: Since $N$ is $\tau_{\mathrm{i}}$-nhd of $g \in X$, then there exists $\tau_{\mathrm{i}}$-open set $\mathrm{G}$ such that $\mathrm{g} \in \mathrm{G} \subseteq N$. Since every $\tau_{\mathrm{i}}$-open set is $\left(\tau_{\mathrm{i}}, \tau_{\mathrm{j}}\right)$ - gr*-open set, $\mathrm{G}$ is $\left(\tau_{\mathrm{i}}, \tau_{\mathrm{j}}\right)$ - gr*-open set. By definition 6.1. $\mathrm{N}$ is $\left(\tau_{\mathrm{i}}, \tau_{\mathrm{j}}\right)$ - gr*-nhd of $\mathrm{X}$.

Remark 6.3. The converse of the above Proposition is need not be true as seen from the following example.

Example 6.4. Let $\mathrm{X}=\{\mathrm{a}, \mathrm{b}, \mathrm{c}\}$ and $\tau_{\mathrm{i}}=\{\mathrm{X}, \phi,\{\mathrm{a}\}\}, \tau_{\mathrm{j}}=\{\mathrm{X}, \phi,\{\mathrm{a}\},\{\mathrm{a}, \mathrm{b}\}\}$

$\mathrm{D}_{\mathrm{r}}^{*} \mathrm{O}\left(\tau_{\mathrm{i}}, \tau_{\mathrm{j}}\right)=\{\mathrm{X}, \phi,\{\mathrm{a}\},\{\mathrm{b}\},\{\mathrm{c}\},\{\mathrm{a}, \mathrm{b}\},\{\mathrm{a}, \mathrm{c}\},\{\mathrm{b}, \mathrm{c}\}\}$, the set $\{\mathrm{b}, \mathrm{c}\}$ is $\left(\tau_{\mathrm{i},}, \tau_{\mathrm{j}}\right)-$ gr*-nhd of $\mathrm{c}$, since there exists a $\left(\tau_{i}, \tau_{j}\right)$ - gr*-open set $\mathrm{G}=\{\mathrm{c}\}$ such that $\mathrm{c} \in\{\mathrm{c}\} \subseteq\{\mathrm{b}, \mathrm{c}\}$. However $\{\mathrm{b}, \mathrm{c}\}$ is not $\tau_{\mathrm{i}}$-nhd of $\mathrm{c}$, since no $\tau_{\mathrm{i}}$-open set $\mathrm{G}$ such that $\mathrm{c} \in \mathrm{G} \subseteq\{\mathrm{b}, \mathrm{c}\}$.

Proposition 6.5. If $\mathrm{N}$ a subset of a bitopological space $\left(\mathrm{X}, \tau_{\mathrm{i}}, \tau_{\mathrm{j}}\right)$ is $\left(\tau_{\mathrm{i}}, \tau_{\mathrm{j}}\right)$ - gr*-open set, then $\mathrm{N}$ is $\left(\tau_{\mathrm{i}}, \tau_{\mathrm{j}}\right)$ - gr*-nhd of each of its points.

Proof: Let $\mathrm{N}$ be a $\left(\tau_{\mathrm{i}}, \tau_{\mathrm{j}}\right)$ - gr*-open set. By Definition 6.1. $\mathrm{N}$ is an $\left(\tau_{\mathrm{i}}, \tau_{\mathrm{j}}\right)$ - gr*-nhd of each of its points.

Proposition 6.6. Let $\left(\mathrm{X}, \tau_{\mathrm{i}}, \tau_{\mathrm{j}}\right)$ be bitopological space:

1) $\forall \mathrm{g} \in \mathrm{X},\left(\tau_{\mathrm{i}}, \tau_{\mathrm{j}}\right)-\mathrm{gr} * \mathrm{~N}(\mathrm{~g}) \neq \phi$

2) $\forall \mathrm{N} \in\left(\tau_{\mathrm{i}}, \tau_{\mathrm{j}}\right)-$ gr*-N(g), then $g \in \mathrm{N}$.

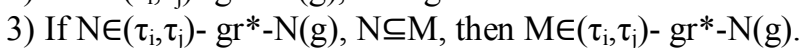

4) If $\mathrm{N} \in\left(\tau_{\mathrm{i}}, \tau_{\mathrm{j}}\right)-$ gr*-N(g), then there exists $\mathrm{M} \in\left(\tau_{\mathrm{i}}, \tau_{\mathrm{j}}\right)$ - gr*-N(g) such that $\mathrm{M} \subseteq \mathrm{N}$ and exists $\mathrm{M} \in\left(\tau_{\mathrm{i}}, \tau_{\mathrm{j}}\right)$ - gr*-N(h), $\forall$ $\mathrm{h} \in \mathrm{M}$.

Proof. 1) Since $\mathrm{X}$ is an $\left(\tau_{\mathrm{i}}, \tau_{\mathrm{j}}\right)$ - gr*-open set, it is $\left(\tau_{\mathrm{i}}, \tau_{\mathrm{j}}\right)$ - gr*-nhd of every geX. Hence there exists at least one $\left(\tau_{\mathrm{i}}, \tau_{\mathrm{j}}\right)$ - gr*-nhd $\mathrm{G}$ for every $\mathrm{g} \in \mathrm{X}$. Therefore $\left(\tau_{\mathrm{i}}, \tau_{\mathrm{j}}\right)$ - gr*-N(g) $\neq \phi, \forall \mathrm{g} \in \mathrm{X}$

2) If $N \in\left(\tau_{i}, \tau_{j}\right)$ - gr* $-N(g)$, then $N$ is $\left(\tau_{i}, \tau_{j}\right)$ - gr*-nhd $G$ of g. Thus By Definition $6.1 \mathrm{~g} \in \mathrm{N}$.

3) If $N \in\left(\tau_{i}, \tau_{j}\right)$ - gr*-N(g), then there is an $\left(\tau_{i}, \tau_{j}\right)$ - gr*-open set $A$ such that $g \in A \subseteq N$, since $N \subseteq M, g \in A \subseteq M$ and $M$ is an $\left(\tau_{i}, \tau_{\mathrm{j}}\right)$ - gr*-nhd of g. Hence $\mathrm{M} \in\left(\tau_{\mathrm{i}}, \tau_{\mathrm{j}}\right)$ - gr*-N(g).

4) If $N \in\left(\tau_{i}, \tau_{j}\right)$ - gr*-N(g), then there exists is an $\left(\tau_{\mathrm{i}}, \tau_{\mathrm{j}}\right)$ - gr*-open set $\mathrm{M}$ such that $\mathrm{g} \in \mathrm{M} \subseteq \mathrm{N}$. Since $\mathrm{M}$ is an $\left(\tau_{\mathrm{i}}, \tau_{\mathrm{j}}\right)$ gr*-open set, then it is $\left(\tau_{\mathrm{i}}, \tau_{\mathrm{j}}\right)$ - gr*-nhd of each of its points. Therefore $\mathrm{M} \in\left(\tau_{\mathrm{i}}, \tau_{\mathrm{j}}\right)$ - gr*-N(h), $\forall \mathrm{h} \in \mathrm{M}$.

\section{Pairwise gr*O-Connected Space}

Definition 7.1. A bitopological space $\left(\mathrm{X}, \tau_{1}, \tau_{2}\right)$ is pairwise gr* $\mathrm{O}$-connected if $\mathrm{X}$ can not be expressed as the union of two non-empty disjoint sets $A$ and $B$ such that $\left[A \cap \tau_{1}-\operatorname{gr} * \mathrm{cl}(\mathrm{B})\right] \cup\left[\tau_{2}-\operatorname{gr} * \mathrm{cl}(\mathrm{A}) \cap \mathrm{B}\right]=\phi$.

Suppose $\mathrm{X}$ can be so expressed then $\mathrm{X}$ is called pairwise gr* $\mathrm{O}$-disconnected and we write $\mathrm{X}=\mathrm{A} \backslash \mathrm{B}$ and call this pairwise gr* O-separation of $\mathrm{X}$.

Theorem 7.3. The following conditions are equivalent for any bitopological space. 
(a) $\mathrm{X}$ is pairwise $\mathrm{gr} * \mathrm{O}$-connected.

(b) X can not be expressed as the union of two non-empty disjoint sets A and B such that A is $\tau_{1^{-}}$gr* open and $\mathrm{B}$ is $\tau_{2}$ - gr* open.

(c) X contains no non-empty proper subset which is both $\tau_{1}$ - gr* open and B is $\tau_{2}$ - gr* closed.

Proof.(a) $\Rightarrow(b)$ : Suppose that $X$ is pairwise gr*O-connected. Suppose that $X$ can be expressed as the union of two non-empty disjoint sets $\mathrm{A}$ and $\mathrm{B}$ such that $\mathrm{A}$ is $\tau_{1-}$ gr* open and $\mathrm{B}$ is $\tau_{2}$ - gr* open. Then $\mathrm{A} \cap \mathrm{B}=\phi$. Consequently $\mathrm{A} \subseteq \mathrm{B}^{\mathrm{C}}$. Then $\tau_{2^{-}}$gr*cl( $\left.\mathrm{A}\right) \subseteq \tau_{2^{-}}$gr*cl( $\left.\mathrm{B}^{\mathrm{C}}\right)=\mathrm{B}^{\mathrm{C}}$. Therefore, $\tau_{2^{-}}$gr*cl( $\left.\mathrm{A}\right) \cap \mathrm{B}=\phi$. Similarly we can prove $\mathrm{A} \cap \tau_{1^{-}}$ $\operatorname{gr} * \operatorname{cl}(\mathrm{B})=\phi$. Hence $\left[\mathrm{A} \cap \tau_{1^{-}} \operatorname{gr} * \mathrm{cl}(\mathrm{B})\right] \cup\left[\tau_{2^{-}} \operatorname{gr} * \mathrm{cl}(\mathrm{A}) \cap \mathrm{B}\right]=\phi$. This is a contradiction to the fact that $\mathrm{X}$ is pairwise gr*O-connected. Therefore, $\mathrm{X}$ can not be expressed as the union of two non-empty disjoint sets $\mathrm{A}$ and

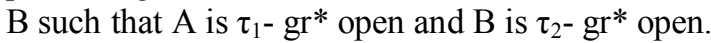

(b) $\Rightarrow(c)$ : Suppose that $X$ can not be expressed as the union of two non-empty disjoint sets A and B such that A is $\tau_{1^{-}}$gr* open and B is $\tau_{2}$ - gr* open. Suppose that $\mathrm{X}$ contains a non-empty proper subset A which is both $\tau_{1^{-}}$gr* open and $\tau_{2}$ - gr* closed. Then $\mathrm{X}=\mathrm{A} \cup \mathrm{A}^{\mathrm{C}}$ where $\mathrm{A}$ is $\tau_{1}$ - gr* open, $\mathrm{A}^{\mathrm{C}}$ is $\tau_{2}$ - gr*open and $\mathrm{A}, \mathrm{A}^{\mathrm{C}}$ are disjoint. This is the contradictions to our assumption. Therefore, $\mathrm{X}$ contains no non-empty proper subset which is both $\tau_{1}$ - $\mathrm{gr} *$ open and $\tau_{2^{-}}$gr* closed.

(c) $\Rightarrow(a)$ : Suppose that $X$ contains no non-empty proper subset which is both $\tau_{1^{-}}$gr* open and $\tau_{2}$ - gr* closed. Suppose that $\mathrm{X}$ is pairwise gr* $\mathrm{O}$-connected. Then $\mathrm{X}$ can be expressed as the union of two non-empty disjoint sets $A$ and $B$ such that $\left[A \cap \tau_{1}-\operatorname{gr} * \operatorname{cl}(B)\right] \cup\left[\tau_{2}-\operatorname{gr} * \operatorname{cl}(A) \cap B\right]=\phi$. Since $A \cap B=\phi$, we have $A=B^{C}$ and $B=A^{C}$.

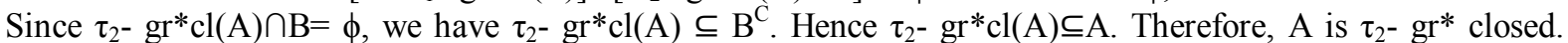
Similarly, B is $\tau_{1}$-gr* closed. Since $A=B^{C}, A$ is $\tau_{1}$ - gr* open. Therefore, there exists a non-empty proper set $A$ which is both $\tau_{1^{-}}$gr* open and $\tau_{2^{-}}$gr* closed. This is the contradiction to our assumption. Therefore, $\mathrm{X}$ is pairwise gr* O-connected.

Theorem 7.4. If $\mathrm{A}$ is pairwise gr*O-connected subset of a bitopological space $\left(\mathrm{X}, \tau_{1}, \tau_{2}\right)$ which has the pairwise gr*O-separation $\mathrm{X}=\mathrm{C} \backslash \mathrm{D}$, then $\mathrm{A} \subseteq \mathrm{C}$ or $\mathrm{A} \subseteq \mathrm{D}$.

Proof. Suppose that $\left(X, \tau_{1}, \tau_{2}\right)$ has the pairwise gr*O-separation $X=C \backslash D$. Then $X=C \cup D$ where $C$ and $D$ are two nonempty disjoint sets such that $\left[C \cap \tau_{1}-\operatorname{gr} * \operatorname{cl}(\mathrm{D})\right] \cup\left[\tau_{2}-\operatorname{gr} * \mathrm{cl}(\mathrm{C}) \cap \mathrm{D}\right]=\phi$. Since $\mathrm{C} \cap \mathrm{D}=\phi$, we have $\mathrm{C}=\mathrm{D}^{\mathrm{C}}$ and $\mathrm{D}=\mathrm{C}^{\mathrm{C}}$. Now $\left[(\mathrm{C} \cap \mathrm{A}) \cap \tau_{1}-\operatorname{gr} * \operatorname{cl}(\mathrm{D} \cap \mathrm{A})\right] \cup\left[\tau_{2}-\operatorname{gr} * \mathrm{cl}(\mathrm{C} \cap \mathrm{A}) \cap(\mathrm{D} \cap \mathrm{A})\right] \subseteq\left[\left(\mathrm{C} \cap \tau_{1}-\operatorname{gr} * \mathrm{cl}(\mathrm{D})\right] \cup\left[\tau_{2}-\operatorname{gr} * \mathrm{cl}(\mathrm{C}) \cap \mathrm{D}\right]=\phi\right.$. Hence $A=(C \cap A) \backslash(D \cap A)$ is pairwise gr*O-separation of $A$. Since A is pairwise gr*O-connected, we have either $(\mathrm{C} \cap \mathrm{A})=\phi$ or $(\mathrm{D} \cap \mathrm{A})=\phi$. Consequently, $\mathrm{A} \subseteq \mathrm{C}^{\mathrm{C}}$ or $\mathrm{A} \subseteq \mathrm{D}^{\mathrm{C}}$. Therefore, $\mathrm{A} \subseteq \mathrm{C}$ or $\mathrm{A} \subseteq \mathrm{D}$.

Theorem 7.5. If $\mathrm{A}$ is pairwise gr* $\mathrm{O}$-connected and $\mathrm{A} \subseteq \mathrm{B} \subseteq \tau_{1}$ - gr*cl(A) $\cap \tau_{2^{-}} \operatorname{gr} * \mathrm{cl}(\mathrm{A})$ then $\mathrm{B}$ is pairwise gr*Oconnected.

Proof. Suppose that $\mathrm{B}$ is not pairwise gr*O-connected. Then $\mathrm{B}=\mathrm{C} \cup \mathrm{D}$ where $\mathrm{C}$ and $\mathrm{D}$ are two nonempty disjoint sets such that $\left[\mathrm{C} \cap \tau_{1^{-}}\right.$gr*cl(D)] $\mathrm{U}\left[\tau_{2^{-}} \mathrm{gr}^{*} \mathrm{cl}(\mathrm{C}) \cap \mathrm{D}\right]=\phi$. Since $\mathrm{A}$ is pairwise gr* $\mathrm{O}$-connected, we have $\mathrm{A} \subseteq \mathrm{C}$ or $\mathrm{A} \subseteq \mathrm{D}$. Suppose $\mathrm{A} \subseteq \mathrm{C}$. Then $\mathrm{D} \subseteq \mathrm{D} \cap \mathrm{B} \subseteq \mathrm{D} \cap \tau_{2^{-}} \operatorname{gr} * \mathrm{cl}(\mathrm{A}) \subseteq \mathrm{D} \cap \tau_{2^{-}} \operatorname{gr} * \mathrm{cl}(\mathrm{C})=\phi$. Therefore, $\phi \subseteq \mathrm{D} \subseteq \phi$. Consequently, $\mathrm{D}=\phi$. Similarly, we can prove $\mathrm{C}=\phi$ if $\mathrm{A} \subseteq \mathrm{D}$ \{by Theorem 7.4\}. This is the contradiction to the fact that $\mathrm{C}$ and $\mathrm{D}$ are nonempty. Therefore, $\mathrm{B}$ is pairwise gr*O-connected.

Theorem 7.6. The union of any family of pairwise gr* $\mathrm{O}$-connected sets having a nonempty intersection is pairwise gr* O-connected.

Proof. Let $I$ be an index set and $i \in I$. Let $A=\cup A_{i}$ where each $A_{i}$ is pairwise gr*O-connected with $\cap A_{i} \neq \phi$. Suppose that $\mathrm{A}$ is not pairwise gr* $\mathrm{O}$-connected. Then $\mathrm{A}=\mathrm{CUD}$, where $\mathrm{C}$ and $\mathrm{D}$ are two nonempty disjoint sets such that

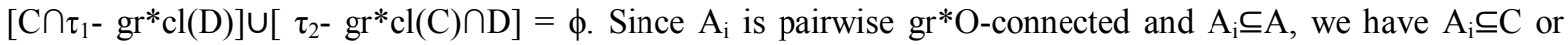
$A_{i} \subseteq D$. Therefore, $U\left(A_{i}\right) \subseteq C$ or $U\left(A_{i}\right) \subseteq D$. Hence, $A \subseteq C$ or $A \subseteq D$. Since $\cap A_{i} \neq \phi$, we have $x \in \cap A_{i}$. Therefore, $x \in$ $A_{i}$ for all i. Consequently, $x \in A$. Therefore, $x \in C$ or $x \in D$. Suppose $x \in C$. Since $C \cap D=\phi$, we have $x \notin D$. Therefore,

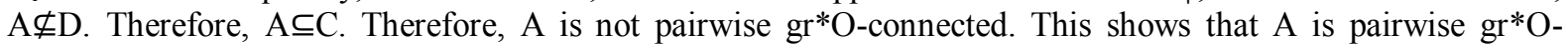
connected.

Theorem 7.7. Let $\mathrm{f}:\left(\mathrm{X}, \tau_{1}, \tau_{2}\right) \rightarrow\left(\mathrm{Y}, \sigma_{1}, \sigma_{2}\right)$ be a pairwise continous bijective and pairwise $\mathrm{r}$ - closed. Then inverse image of a $\sigma_{\mathrm{i}^{-}}$gr* closed set is $\tau_{\mathrm{i}^{-}}$gr* closed.

Theorem 7.8. Let $\mathrm{f}:\left(\mathrm{X}, \tau_{1}, \tau_{2}\right) \rightarrow\left(\mathrm{Y}, \sigma_{1}, \sigma_{2}\right)$ be a pairwise continous bijective and pairwise $\mathrm{r}$ - closed function. Then the image of a pairwise gr* $\mathrm{O}$-connected space under $\mathrm{f}$ is pairwise gr* $\mathrm{O}$-connected.

Proof. Let $\mathrm{f}:\left(\mathrm{X}, \tau_{1}, \tau_{2}\right) \rightarrow\left(\mathrm{Y}, \sigma_{1}, \sigma_{2}\right)$ be a pairwise continous surjection and pairwise $\mathrm{r}$ - closed. Let $\mathrm{X}$ is pairwise gr*O-connected. Suppose that $\mathrm{Y}$ is pairwise gr*O-disconnected. Then $\mathrm{Y}=\mathrm{A} \cup \mathrm{B}$ where $\mathrm{A}$ is $\sigma_{1}$ - gr* open and B is $\sigma_{2}$ - gr* open in Y. Since $f$ is pairwise continuous and pairwise $r$-closed, we have $f^{1}(A)$ is $\tau_{1}$ - gr* open and $f^{1}(B)$ is $\tau_{2}$ - gr* open in $X$. Also $X=f^{1}(A) \cup f^{1}(B), f^{1}(A)$ and $f^{1}(B)$ are two nonempty disjoint sets. Then $X$ is pairwise gr* $\mathrm{O}$-disconnected. This is the contradiction to the fact that $\mathrm{X}$ is pairwise gr*O-connected. Therefore, $\mathrm{Y}$ is pairwise gr* $\mathrm{O}$-connected. 


\section{Pairwise gr*O-Compact Space}

Definition 8.1. A nonempty collection $\zeta=\left\{A_{i}, i \in I\right.$, an index set $\}$ is called a pairwise gr* open cover of a bitopological space $\left(\mathrm{X}, \tau_{1}, \tau_{2}\right)$ if $\mathrm{X}=\mathrm{UA}_{\mathrm{i}}$ and $\zeta \subseteq \tau_{1^{-}} \operatorname{gr} * \mathrm{O}\left(\mathrm{X}, \tau_{1}, \tau_{2}\right) \cup \tau_{2^{-}} \mathrm{gr}{ }^{*} \mathrm{O}\left(\mathrm{X}, \tau_{1}, \tau_{2}\right)$ and $\zeta$ contains at least one member of $\tau_{1}$ - gr* $\mathrm{O}\left(\mathrm{X}, \tau_{1}, \tau_{2}\right)$ and one member of $\tau_{2}$ gr* $\mathrm{O}\left(\mathrm{X}, \tau_{1}, \tau_{2}\right)$.

Defintion 8.2. A bitopological space $\left(\mathrm{X}, \tau_{1}, \tau_{2}\right)$ is pairwise gr*O-compact if every pairwise gr* open cover of $\mathrm{X}$ has a finite subcover.

Definition 8.3. A set $\mathrm{A}$ of a bitopological space $\left(\mathrm{X}, \tau_{1}, \tau_{2}\right)$ is pairwise gr*O-compact relative to $\mathrm{X}$ if every pairwise gr* open cover of $\mathrm{B}$ by has a finite subcover as a subspace.

Theorem 8.5 . Every pairwise $\mathrm{gr} * \mathrm{O}$-compact space is pairwise compact.

Proof. Let $\left(X, \tau_{1}, \tau_{2}\right)$ be pairwise gr*O-compact. Let $\zeta=\left\{A_{i}, i \in I\right.$, an index set $\}$ be a pairwise open cover of $X$. Then $\mathrm{X}=\mathrm{UA} \mathrm{A}_{\mathrm{i}}$ and $\zeta \subseteq \tau_{1} \cup \tau_{2}$ and $\zeta$ contains at least one member of $\tau_{1}$ and one member of $\tau_{2}$. Since every $\tau_{\mathrm{i}}$-open set is $\tau_{i^{-}}$gr* open, we have $\mathrm{X}=\bigcup \mathrm{A}_{\mathrm{i}}$ and $\zeta \subseteq \tau_{1^{-}} \operatorname{gr} * \mathrm{O}\left(\mathrm{X}, \tau_{1}, \tau_{2}\right) \cup \tau_{2^{-}} \operatorname{gr} * \mathrm{O}\left(\mathrm{X}, \tau_{1}, \tau_{2}\right)$ and $\zeta$ contains at least one member of $\tau_{1}$ - gr* $\mathrm{O}\left(\mathrm{X}, \tau_{1}, \tau_{2}\right)$ and one member of $\tau_{2}$ - $\mathrm{gr} * \mathrm{O}\left(\mathrm{X}, \tau_{1}, \tau_{2}\right)$. Therefore, $\zeta$ is the pairwise gr*-open cover of $\mathrm{X}$. Since $\mathrm{X}$ is pairwise gr*O-compact, we have $\zeta$ has the finite subcover. Therefore, $\mathrm{X}$ is pairwise compact.

But the converse of the above theorem need not be true in general.

Theorem 8.6. Let $\mathrm{f}:\left(\mathrm{X}, \tau_{1}, \tau_{2}\right) \rightarrow\left(\mathrm{Y}, \sigma_{1}, \sigma_{2}\right)$ be a pairwise continous, bijective and pairwise $\mathrm{r}-\mathrm{closed}$. Then the image of a pairwise gr* $\mathrm{O}$-compact space under $\mathrm{f}$ is pairwise gr* $\mathrm{O}$-compact.

Proof. Let $\mathrm{f}:\left(\mathrm{X}, \tau_{1}, \tau_{2}\right) \rightarrow\left(\mathrm{Y}, \sigma_{1}, \sigma_{2}\right)$ be a pairwise continous surjection and pairwise r-closed. Let $\mathrm{X}$ be pairwise gr*O-compact. Let $\zeta=\left\{\mathrm{A}_{\mathrm{i}}, \mathrm{i} \in \mathrm{I}\right.$, an index set $\}$ be a pairwise gr*-open cover of $\mathrm{Y}$. Then $\mathrm{Y}=\bigcup \mathrm{U}_{\mathrm{i}}$ and $\zeta \subseteq \sigma_{1}$ gr* $\mathrm{O}\left(\mathrm{Y}, \sigma_{1}, \sigma_{2}\right) \cup \sigma_{2}$ - gr* $\mathrm{O}\left(\mathrm{Y}, \sigma_{1}, \sigma_{2}\right)$ and $\zeta$ contains at least one member of $\sigma_{1}$ - gr* $\mathrm{O}\left(\mathrm{Y}, \sigma_{1}, \sigma_{2}\right)$ and one member of $\sigma_{2^{-}}$gr* $\mathrm{O}\left(\mathrm{Y}, \sigma_{1}, \sigma_{2}\right)$. Therefore, $\mathrm{X}=\mathrm{f}^{1}\left[\mathrm{U}\left(\mathrm{A}_{\mathrm{i}}\right)\right]=U \mathrm{f}^{1}\left(\mathrm{~A}_{\mathrm{i}}\right)$ and $\mathrm{f}^{1}(\zeta) \subseteq \tau_{1^{-}} \operatorname{gr} * \mathrm{O}\left(\mathrm{X}, \tau_{1}, \tau_{2}\right) \cup \tau_{2^{-}} \operatorname{gr} * \mathrm{O}\left(\mathrm{X}, \tau_{1}, \tau_{2}\right)$ and $\mathrm{f}$ ${ }^{1}(\zeta)$ contains at least one member of $\tau_{1^{-}} \operatorname{gr} * \mathrm{O}\left(\mathrm{X}, \tau_{1}, \tau_{2}\right)$ and one member of $\tau_{2^{-}} \operatorname{gr} * \mathrm{O}\left(\mathrm{X}, \tau_{1}, \tau_{2}\right)$. Therefore, $\mathrm{f}^{1}(\zeta)$ is the pairwise gr*-open cover of $X$. Since $X$ is pairwise gr*O-compact, we have $X=U f^{1}\left(A_{i}\right), i=1 \ldots . n$. $\Rightarrow$ $\mathrm{Y}=\mathrm{f}(\mathrm{X})=\mathrm{U}\left(\mathrm{A}_{\mathrm{i}}\right), \mathrm{i}=1 \ldots \mathrm{n}$. Hence, $\zeta$ has the finite subcover. Therefore, $\mathrm{Y}$ is pairwise gr*O-compact.

Theorem 8.7. If $\mathrm{Y}$ is $\tau_{1}$ - gr* closed subset of a pairwise gr*O-compact space $\left(\mathrm{X}, \tau_{1}, \tau_{2}\right)$, then $\mathrm{Y}$ is $\tau_{2^{-}}$gr* $\mathrm{O}$ compact.

Proof. Let $\left(X, \tau_{1}, \tau_{2}\right)$ be a pairwise gr*O-compact space. Let $\zeta=\left\{A_{i}, i \in I\right.$, an index set $\}$ be a $\tau_{2^{-}}$gr* open cover of $\mathrm{Y}$. Since $\mathrm{Y}$ is $\tau_{1}$ - gr* closed subset, $\mathrm{Y}^{\mathrm{C}}$ is $\tau_{1}$ - gr* open. Also $\zeta \cup \mathrm{Y}^{\mathrm{C}}=\mathrm{Y}^{\mathrm{C}} \cup\left\{\mathrm{A}_{\mathrm{i}}, \mathrm{i} \in \mathrm{I}\right.$, an index set $\}$ be a pairwise gr* open cover of $X$. Since $X$ is pairwise gr*O-compact, $X=Y^{C} \cup A_{1} \cup \ldots \ldots \cup A_{n}$. Hence $Y=A_{1} \cup \ldots \ldots \cup A_{n}$. Therefore, $\mathrm{Y}$ is $\tau_{2}$ - gr* $\mathrm{O}$-compact.

Since every $\tau_{1}$-closed set is $\tau_{1}$ - gr* closed, we have the following.

Therorem 8.8. If $\mathrm{Y}$ is $\tau_{1}$-closed subset of a pairwise gr* $\mathrm{O}$-compact space $\left(\mathrm{X}, \tau_{1}, \tau_{2}\right)$, then $\mathrm{Y}$ is $\tau_{2}$ - gr* $\mathrm{O}$-compact. Theorem 8.9. If $\left(X, \tau_{1}\right)$ and $\left(X, \tau_{2}\right)$ are Hausdorff and $\left(X, \tau_{1}, \tau_{2}\right)$ is pairwise gr*O-compact, then $\tau_{1}=\tau_{2}$.

Proof. Let $\left(X, \tau_{1}\right)$ and $\left(X, \tau_{2}\right)$ are Hausdorff and $\left(X, \tau_{1}, \tau_{2}\right)$ is pairwise gr*O-compact. Since every pairwise gr*Ocompact space is pairwise compact, we have $\left(X, \tau_{1}\right)$ and $\left(X, \tau_{2}\right)$ are Hausdorff and $\left(X, \tau_{1}, \tau_{2}\right)$ is pairwise compact. Let $\mathrm{F}$ be $\tau_{1}$-closed in $\mathrm{X}$. Then $\mathrm{F}^{\mathrm{C}}$ is $\tau_{1}$-open in $\mathrm{X}$. Let $\zeta=\left\{\mathrm{A}_{\mathrm{i}}, \mathrm{i} \in \mathrm{I}\right.$, an index set $\}$ be the $\tau_{2}$-open cover for $\mathrm{X}$. Therefore, $\zeta \cup F^{C}$ is the pairwise open cover for $X$. Since $X$ is pairwise compact, $X=F^{C} \cup A_{1} \cup \ldots \ldots \cup A_{n}$. Hence $F=A_{1} \cup \ldots \ldots \cup A_{n}$. Hence $F$ is $\tau_{2}$-compact. Since $\left(X, \tau_{2}\right)$ is Hausdorff, we have $F$ is $\tau_{2}$-closed. Similarly, every $\tau_{2}$-closed set is $\tau_{1}$-closed. Therefore $\tau_{1}=\tau_{2}$.

[1] I. Arokiarani. Studies on generalizations of generalised closed sets and maps in topological spaces. Ph.D. Thesis, Bharathiar University, Coimbatore-1997.

[2] T.Fukutake. On generalized closed sets in bitopological spaces. Bull. Fukuoka Univ. Ed. Part-III, 35:19:28(1985).

[3] T. Fukutake, P. Sundaram, and N. Nagaveni. On weakly generalized closed sets and weakly generalized continuous in topological spaces. Bull. Fukuoda Univ. Ed. Part, 48:33:40 (1999).

[4] T. Fukutake, P.Sundaram, and M. Sheik John. W-closed sets, W-open sets and W-continuity in bitoplogical spaces. Bull. Fukuoka Univ. Ed. Part III, 51:1:9(2002).

[5] K. Indirani, P. Sathishmohan and V. Rajendran, On gr ${ }^{*}$-Closed Sets in a Topological Spaces, Int. Jr. of Math. Trends and Technology, 6(2)(2014).

[6] K. Indirani, P. Sathishmohan and V. Rajendran, On gr*- Continuous Functions in Topological Spaces, Int. Jr. of Sci. Engg. and Tech. Research, 5(4)(2014).

[7]. J.C.Kelley. Bitopological spaces. Proc. London Math. Soc., 13:71:89, 1963.

[8] N. Levine, Semi-open sets and semi-continuity in topological Spaces, Amer.Math.Monthly, 70:36:41(1963).

[9] N. Levine, Generalized closed sets in topology, Rend. Circ. Math. Palermo, 19(2):89:96(1970).

[10] H. Maki, P. Sundram and K. Balachandran, Semi-generalized continuous maps in a Topological Spaces, Bull. Fukuko Univ. Ed. Part III, 40:33:40 (1991).

[11] M. Stone, Applications of the theory of Boolean rings to general topology, Trans. Amer. Math. Soc., 41:374:381(1937).

[12] M. Sheik John and P.Sundaram. g*-closed sets in bitopological spaces. Indian J.pure and appl. Math., 35(1):71:80 (2004). 